Revista ACB: Biblioteconomia em Santa Catarina, Florianópolis, v. 22, n. 2, ESPECIAL, p. 192-207, abr./ jul., 2017.

Anais do $35^{\circ}$ Painel Biblioteconomia Santa Catarina.

Chapecó

Recebido em: 16-03-2017 Aceito em: 05-05-2017

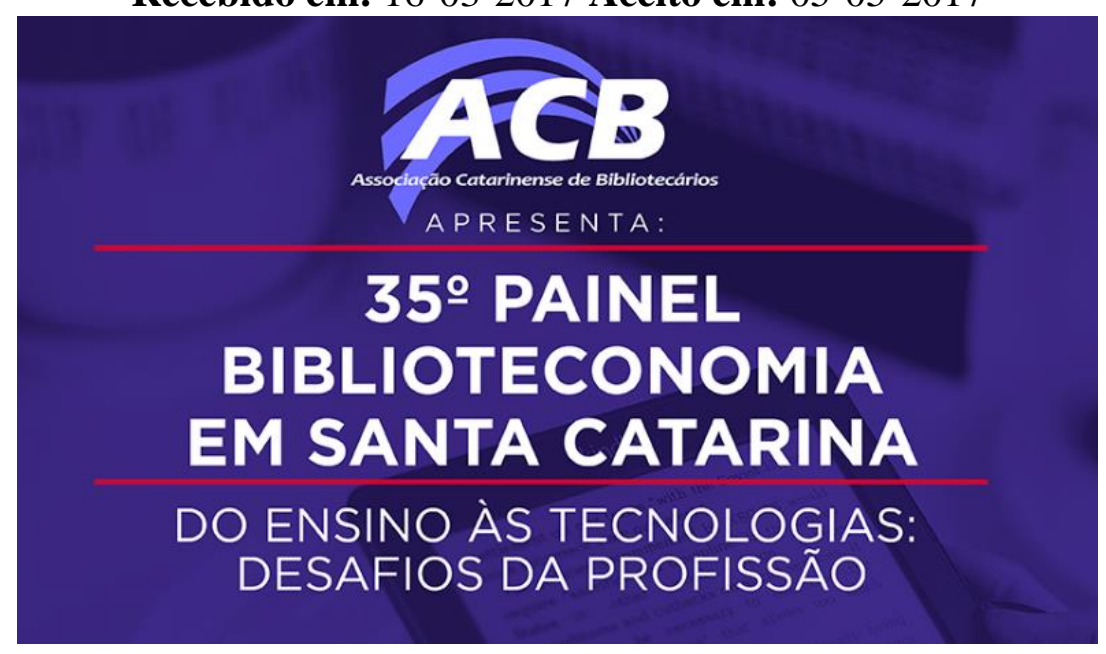

\title{
MÚLTIPLOS OLHARES EM PRÓ DA QUALIDADE DE SERVIÇOS BIBLIOTECONÔMICOS: SERVQUAL E O PROCESSO DE DESENVOLVIMENTO DE SERVIÇOS EM UMA BIBLIOTECA ACADÊMICA NO SÉCULO XXI ${ }^{1}$
}

\section{Marcelo Calderari Miguel ${ }^{2}$}

\begin{abstract}
Resumo: Avalia a qualidade dos serviços prestados no Serviço de Referência da Biblioteca Setorial do Centro de Educação da Universidade Federal do Espírito Santo (UFES) utilizando o método Servqual. Examina a matriz importância e satisfação como ferramenta para análise dos dados em relação às cinco dimensões da qualidade: Confiabilidade, Empatia, Garantia, Receptividade e Tangibilidade. A metodologia deste estudo possui caráter descritivo de natureza quantitativa. Seu delineamento é do tipo levantamento com a utilização de questionário online semiestruturado. Os resultados obtidos nesta pesquisa evidência que os clientes consideram a dimensão Tangilidade importante, no entanto, há insatisfação. Recomenda o método Servqual para avaliação da qualidade de biblioteca acadêmica.
\end{abstract}

Palavras-chave: Servqual. Serviço de Referência. Qualidade. Biblioteca Acadêmica.

\section{INTRODUÇÃO}

$\mathrm{Na}$ era digital as bibliotecas físicas sobrevivem às Tecnologias de Informação e Comunicação (TIC). Por conta desse fato, a atuação dos bibliotecários tem sido um tema muito discutido na atualidade, especialmente, no que se refere a mudança de paradigma da "posse" para o "acesso" à informação. Assim, o trabalho dos bibliotecários precisa ser pautado pelo paradigma alternativo, isto é, o trabalho com foco nos usuários visando a prestação de serviços e produtos diferenciados.

No presente artigo pretende-se abordar o seguinte problema: qual percepção e expectativa dos usuários acerca da qualidade do serviço de referência (SR) prestado pela Biblioteca do Centro de

\footnotetext{
${ }^{1}$ Este artigo derivou da conexão de saberes e orientação dos Profs. Rogério Zanon da Silveira (Dr. em Administração e Docente do Curso de administração na Ufes) e Dulcinea Sarmento Rosemberg (Dr. ${ }^{a}$ em Educação, Docente de Curso de Biblioteconomia na Ufes e coordenadora do Doutorado Interinstitucional em Ciência da Informação UnB/Ufes).

${ }^{2}$ Graduado em Biblioteconomia pela Universidade Federal do Espírito Santo (Ufes). Bacharel em Ciência Contábeis pela Faculdade de Estudos Administrativos de Minas Gerais (FEAD).
} 
Revista ACB: Biblioteconomia em Santa Catarina, Florianópolis, v. 22, n. 2, ESPECIAL, p. 192-207, abr./ jul., 2017.

Anais do $35^{\circ}$ Painel Biblioteconomia Santa Catarina.

Chapecó

Educação $(\mathrm{CE})^{3}$ da Universidade Federal do Espírito Santo (Ufes). O objetivo principal da pesquisa é avaliar a qualidade dos serviços prestados no que tange a expectativa e a percepção dos usuários em relação ao SR da biblioteca do CE/Ufes, utilizando o Servqual (Service Quality Gap Analysis) - uma ferramenta de avaliação da qualidade.

Analisando, toda essa trajetória, este trabalho se justifica pela relevância das discussões em torno da "qualidade de serviços de informação" e as possibilidades de contribuir, especificamente, para a melhoria do SR em Bibliotecas Acadêmicas. Em suma, ao dirigirmos o olhar para o estudo da qualidade do SR da Biblioteca do CE/Ufes, o fazemos tendo em conta os seguintes aspectos da relevância desta pesquisa com os seus usuários: a) científico: visa contribuir como mais uma fonte de conhecimento sobre a qualidade do SR em uma biblioteca setorial de uma IES. b) social: a tomada de decisão com base nos resultados obtidos poderá levar a melhoria do atendimento aos usuários, tornando a relação entre SR e os clientes mais eficaz e satisfatória. c) institucional: o mapeamento das expectativas e das percepções dos usuários permitirá estabelecer uma política de atendimento à comunidade usuária. d) acadêmico: ampliar o entendimento sobre a qualidade de serviços prestados pela área de biblioteconomia no que ser refere à acuidade e aprimoramento de um SR.

Diante da acepção de melhoria da qualidade dos serviços públicos de um modo geral, o reitor da Ufes, professor Reinaldo Centoducatte vem anunciando que a Universidade caminha para alcançar um padrão de excelência acadêmica em diferentes áreas do conhecimento, tendo como o objetivo primordial a busca da qualidade de todas as suas ações acadêmicas (META DA UFES É AMPLIAR A QUALIDADE, 2013, p.56).

Com esse entendimento fomos autorizados a realizar este estudo de usuários para conhecer as expectativas e percepções da clientela da Biblioteca do CE da Ufes. Para isso, adotamos a abordagem teórico-metodológica Servqual. Mas, por que denominamos o Servqual como uma abordagem teóricometodológica? Porque fornece um corpus teórico sobre inúmeros conceitos, tais como: qualidade, satisfação, percepção, expectativa, serviços, entre outros conceitos e, ao mesmo tempo, apresenta uma metodologia científica capaz de levar à concretização de estudos que tenham como objeto de estudo a satisfação dos usuários dos serviços prestados por quaisquer organizações.

\footnotetext{
${ }^{3}$ Os centros de ensino são unidades acadêmico-administrativas e a Ufes possui nove centros: Centro de Artes (CAr), Centro de Ciências Agrárias (CCA), Centro de Ciências Exatas (CCE), Centro de Ciências Humanas e Naturais (CCHN), Centro de Ciências Jurídicas e Econômicas (CCJE), Centro de Ciências da Saúde (CCS),Centro de Educação (CE), Centro de Educação Física e Desportos (CEFD), Centro Tecnológico (CT).
} 
Revista ACB: Biblioteconomia em Santa Catarina, Florianópolis, v. 22, n. 2, ESPECIAL, p. 192-207, abr./ jul., 2017.

Anais do $35^{\circ}$ Painel Biblioteconomia Santa Catarina.

Chapecó

\section{REVISÃO DE LITERATURA}

Desde meados do século XX o discurso biblioteconômico vem apresentando em seu cerne preocupações com os usuários e não usuários. Daí a enunciação das teses de Grogan (1995) e de Figueiredo (1999), que corroboram a importância do SR. Não há dúvidas, garante Grogan (1995), que os trabalhadores responsáveis pelo SR consideram-no a pedra angular da prática ${ }^{4}$ profissional, sendo ele muito mais do que um serviço técnico especializado ou uma habilidade profissional, trata-se de uma atividade essencialmente humana que atende aos anseios de conhecer e compreender.

Grogan (1995) reporta que o SR é um ato social, e também uma relação humana, por mais breve que seja, tem um status ímpar, caracterizando-se por envolver uma relação pessoal face a face, que o torna mais humano dos serviços da biblioteca; e, em segundo lugar pela certeza antecipada de que o “esforço despendido provavelmente não se desmanchará no ar” (GROGAN, 1995, p. 33-34).

Além das necessidades expressas dos usuários, Lancaster (1996) aponta ser imprescindível que a biblioteca compreenda as necessidades latentes que não se transformam em demandas, bem como as necessidades potenciais dos não-usuários sob o risco de ficar estagnada na prestação de serviços, o que representa estar em vias de obsolescência. Alinhados com esse cenário, Britto e Vergueiro (2011) mostram que os profissionais da informação têm como premissa fornecer a informação correta e no momento certo ao usuário, outras duas leis de Ranganathan.

O SR como vitrine institucional é um campo fecundo de estudos na biblioteconomia. A Accart (2012, p. 4) nota que SR no campo virtual ou pelo menos a distância aparece em 1934 no trabalho de Paul Otlet e, aponta em sua obra que o SR deve primar pela qualidade.

O enfoque de qualidade é mais do que uma tendência, pois se inscreve numa política global de serviços, a fim de melhorar as atividades. Adotando uma abordagem de qualidade, e isso em todos os níveis da relação de serviço, o serviço e a equipe de referência se posicionam como um elemento-chave da instituição (ACCART, 2012, p. 274).

Portanto, nos últimos anos as instituições tem avançado na direção de um comprometimento com a qualidade dos serviços prestados. Esse movimento é percebido a partir de algumas leis e programas instituídos na gestão universitária. Nessa direção, Brito e Vergueiro (2011) indicam que à Medida Provisória $n^{\circ} 147 / 2003$, transformada na Lei $n^{\circ}$ 10.861/2004, instituiu o Sistema Nacional de Avaliação da Educação Superior (SINAES) com o objetivo de assegurar o processo nacional de avaliação das IES, dos cursos de graduação e do desempenho acadêmico de seus estudantes.

\footnotetext{
${ }^{4}$ Grogan (1995) aponta oitos processos abrangente contidos no SR: o problema, a necessidade de informação, a questão inicial, a questão negociada, a estratégia de busca, o processo de busca, a resposta e a solução. Já Accart (2012) reporta que o SR é uma atividade que entrelaçam competência intelectual, conhecimento técnico e relação como o usuário; tocando assim, no cerne da profissão de bibliotecário, o SR deve ser um serviço de qualidade, concebido com uma orientação que privilegia os usuários.
} 
Revista ACB: Biblioteconomia em Santa Catarina, Florianópolis, v. 22, n. 2, ESPECIAL, p. 192-207, abr./ jul., 2017.

Anais do $35^{\circ}$ Painel Biblioteconomia Santa Catarina.

Chapecó

Nessa perspectiva, existem várias razões para que os gestores incorporem práticas de avaliação em unidades de informação. Lancaster (1996) assinala quatro motivos para tal jeito de trabalhar: (I) estabelecer uma escala para mostrar em que nível de desempenho o serviço está funcionando no momento; (II) comparar o desempenho de várias bibliotecas ou serviços; (III) justificar sua existência simplesmente; e (IV) identificar as possíveis causas de insucessos ou ineficiência dos serviços ou ainda uma análise da relação custo-benefício (LANCASTER,1996).

Almeida Júnior (2003) recomendam que os bibliotecários apliquem nos processos avaliativos definindo com clareza, delineando os instrumentos de avaliação de modo a responder questões específicas às suas inquietações e dos usuários. Agindo assim, a avaliação se faz necessária, pois é ela quem direciona qualquer mudança, transformação, realinhamento, manutenção e, até mesmo, o fim de uma ação. Sem avaliação, qualquer ação é exercida às cegas [...] (ALMEIDA JÚNIOR, 2003, p. 107).

\subsection{Estudos de usuários como ferramenta de gestão da qualidade}

Para Almeida Júnior (2003) o usuário não pode ser entendido como um mero receptor dos serviços, antes é necessário compreendê-lo como um participante ativo que auxilia a tomada de decisão. Enfim, ainda para o autor (2003, p. 203), o "Outro lado importante que se traduz como alerta, é o fato de que não é o usuário o objeto de avaliação, mas o serviço do qual ele faz parte”.

Reportando-se ao bibliotecário, Ferreira (1995) diz que esse profissional deve ter sensibilidade para entender as necessidades e limitações de seus clientes e assim, como gestor de um novo tipo de biblioteca, ele deve guiar a comunidade para a satisfação de suas necessidades informacionais. Em sintonia com essas premissas, Accart (2012, p. 114) lembra que “[...] um usuário satisfeito volta, se encontrar quem o ouça, quem lhe dê atenção e, naturalmente, a resposta certa para suas dúvidas [...]”.

O usuário é considerado, portanto, como um elemento fundamental da política global da instituição, sendo colocado em seu centro: discussões, estudos e consultorias permitem melhor focar suas necessidades [...] Este serviço é o verdadeiro ponto de encontro como o usuário, o desfecho de todo o trabalho precedente com os documentos (resumindo nas operações da cadeia documentária). Atualmente, mesmo a situação do atendimento tendo mudado, ainda deve ser melhorada (ACCART, 2012, p. 213-214).

Por ser assim, adotamos o paradigma alternativo para realizar o presente estudo de usuários, que coloca o usuário numa posição ativa (FIGUEIREDO,1999; ARAÚJO, 2010), levando a ser o foco de atenção das unidades de informação.

Desde o final da década de 1970, diversos pesquisadores envolveram na construção de modelos teóricos para entender melhor o processo pelo qual os usuários sentem necessidade e se engajam na busca e uso de informação. Sustentados por uma perspectiva cognitivista, autores como Belkin (1980), Wilson (1981), Dervin (1983), Taylor (1986), Elis (1989) e Kuhlthau (1991) começaram a 
Revista ACB: Biblioteconomia em Santa Catarina, Florianópolis, v. 22, n. 2, ESPECIAL, p. 192-207, abr./ jul., 2017.

Anais do $35^{\circ}$ Painel Biblioteconomia Santa Catarina.

Chapecó

desenvolver modelos para a compreensão do 'comportamento informacional' dos usuários. Esse conjunto de estudos recebeu o nome de "abordagem alternativa" (DERVIN; NILAN, 1986) por se contrapor ao outro modelo que entendia a informação como algo objetivo, dotado de sentido em si. Ao contrário, a abordagem alternativa buscava ver o que a informação é da perspectiva de quem a usa, do usuário. Essa perspectiva de quem foi introduzida no Brasil na metade da década de 1990 (FERREIRA, 1995; MARTUCCI, 1997). Desde então [...] a informação é entendida como um recurso usado por um sujeito diante de uma situação de lacuna ou estado vazio de conhecimento. (ARAÚJO, 2010, p. 25).

A abordagem alternativa (GONÇALVES, 2013) e, mais recentemente, a social com seus desdobramentos e peculiaridades "traz a tona" um usuário em incessante processo de construção - livre para indicar o que deseja junto aos sistemas ou às conjunturas em que se situam, avaliando suas necessidades cognitivas, afetivas e fisiológicas próprias que coexistem dentro de uma ambiência institucional. Em suma, cabe lembrar o ditado do professor Antônio Houaiss, citado por Fonseca (2007): "sempre haverá bibliotecários celestes e bibliotecários pedestres".

Convém lembrar, que adotamos uma abordagem (re)adaptada e portanto, tal modelagem torna viável avaliar a qualidade num cenário em que os serviços prestados podem variar. Miguel e Freire (2016) lembram que cada indivíduo que constitui uma equipe de trabalho ${ }^{5}$ possui jeitos e características particulares de acolher e recepcionar, modos de se colocar à disposição, de compreender, ser e fazer singulares.

\subsection{Dimensão conceitual de qualidade de serviço e suas implicações}

Hodiernamente as mudanças são cada vez mais rápidas e identifica-se que a preocupação com a qualidade de bens e serviços não é recente. A Revolução Industrial durou duzentos anos (1750-1950), naquele período o maior desafio foi a eficiência, fazer o maior número de coisas no menor tempo, aumentar a produtividade para agregar valor à organização. A história da civilização mostra que a agricultura precisou de dez mil anos para produzir a indústria e a sociedade capitalista em aproximadamente duzentos anos produziu a era Pós-Industrial, em que o trabalho físico é produzido pelas máquinas, o mental pelos computadores e o criativo, uma tarefa que por enquanto, ainda é considerada indelegável para a inteligência artificial e realizada apenas pelos seres humanos (ASSIS, 2008).

Neste cenário, Britto e Vergueiro (2011) mostram que a preocupação com a qualidade de bens e serviços não é recente, teve início na década de 1920, com a criação do Controle Estatístico de Processo (CEP) e do Ciclo PDCA (Plan, Do, Ckeck e Act, ou planejar, executar, verificar e agir), chegando à gestão da qualidade total na década de 1950.

5 Assim é comum que cada colaborador tenha um desempenho diferenciado mesmo que a organização implante processos de padronização para alcançar a qualidade almejada 
Revista ACB: Biblioteconomia em Santa Catarina, Florianópolis, v. 22, n. 2, ESPECIAL, p. 192-207, abr./ jul., 2017. Anais do $35^{\circ}$ Painel Biblioteconomia Santa Catarina.

Chapecó

Já Parasuraman, Zeithaml e Berry (1985) iniciaram uma extensa pesquisa de natureza exploratória para ratificar os fatores determinantes da qualidade de serviço, abrangendo os seguintes objetivos: (a) rever o pequeno número de estudos existentes que investigaram qualidade de serviço; (b) divulgar os conhecimentos obtidos em uma extensa investigação exploratória de qualidade em quatro empresas de serviços; (c) desenvolver um modelo conceitual de qualidade de serviço; (d) oferecer propostas para estimular pesquisas futuras sobre a qualidade.

Conceitualmente, a "qualidade" pode ser definida de distintas formas. Neste estudo escolheu-se o conceito de Parasuraman, Berry e Zeithaml (1985). Para esses autores, "qualidade" é a diferença entre as expectativas dos clientes sobre o serviço a receber e suas percepções sobre os serviços efetivamente recebidos. No julgamento de um serviço pode haver diferenças entre o que a biblioteca oferece e o que de fato o usuário necessita. Esse desalinhamento resulta tanto na falha da biblioteca em satisfazer as necessidades dos clientes como também nas expectativas irreais deles. Portanto não basta fornecer serviços com excelente qualidade, é necessário que as organizações estruturem processos contínuos para monitorar as percepções dos clientes sobre a sua qualidade de serviços.

O "Modelo Conceitual da Qualidade de Serviço" apresenta as situações em que podem ocorrer os Gaps entre as expectativas e percepções dos clientes. No modelo, fica explícito que a qualidade dos serviços é influenciada pelos comportamentos dos funcionários mediante as cinco dimensões: tangibilidade (tangibles), confiabilidade (reliability), sensibilidade/receptividade (responsiveness), segurança/garantia (assurance) e empatia (empathy).

Confiabilidade: A capacidade de prestar o serviço prometido de modo confiável e com precisão. Tangíveis: A aparência física de instalações, equipamentos, pessoal e materiais de comunicação. Sensibilidade: a disposição para ajudar o cliente e proporcionar com presteza um serviço. Segurança: O conhecimento e a cortesia de empregados e sua habilidade em transmitir confiança e confiabilidade. Empatia: A atenção e o carinho individualizados proporcionados aos clientes. (BERRY; PARASURAMAN, 1992, p. 30).

A dimensão Tangibilidade em bibliotecas acadêmicas, a atualização de equipamentos de informática (hardware e software) é relevante, por exemplo, para tornar ágeis as pesquisas dos usuário. Aparência também importa, pois afeta a percepção em relação à qualidade do serviço.

A dimensão Confiabilidade na perspectiva de um cliente de biblioteca acadêmica, confiabilidade é relevante, pois aponta à dependência obrigatória em relação aos serviços prestados pela instituição. Se o serviço não for prestado com precisão e no prazo estipulado, pode incorrer danos irreparáveis, como por exemplo, um usuário pesquisador deixar de citar um texto proeminente por demora no serviço de empréstimo de acervo interbibliotecas. 
Revista ACB: Biblioteconomia em Santa Catarina, Florianópolis, v. 22, n. 2, ESPECIAL, p. 192-207, abr./ jul., 2017.

Anais do $35^{\circ}$ Painel Biblioteconomia Santa Catarina.

Chapecó

A dimensão Receptividade procede da categoria Sensibilidade, denota uma redução do tempo despendido pelo usuário em questões atinentes aos serviços de informação, ou seja, ofertando presteza no processo de pesquisa.

A dimensão Garantia sintetiza as categorias Competência, Cortesia, Comunicação, Credibilidade e Segurança. Nesta dimensão, é dado mais ênfase aos trabalhadores, em comparação com a dimensão Confiança, que se relaciona, no conjunto deste trabalho, com a qualidade de serviço da biblioteca acadêmica, enquanto instituição prestadora de serviços de informação.

Por fim, a dimensão Empatia concentra as categorias Acesso e Compreensão. Em bibliotecas acadêmicas, essa dimensão é relevante, pois cada pesquisa tem objetivos distintos; a forma de pesquisar e os conhecimentos atinentes às diversas possibilidades metodológicas para cada usuário.

A satisfação é uma avaliação feita pelo cliente e acontece quando um serviço atende ou não as suas necessidades e expectativas. Para Parasuraman, Zeithaml e Berry (1985) a satisfação dos clientes está diretamente ligada às suas percepções quanto à qualidade dos serviços. A falha em alcançar estas necessidade e expectativas é o que causa a insatisfação no processo de serviços (MIGUEL; FREIRE, 2016).

Em face do exposto, mensurar o valor percebido engendra o processo de tomada de decisão. Destarte, para superar as dificuldades e adaptar o SR aos desejos, necessidades e características dos usuários e, incrementar o direcionamento estratégico e o aprimoramento da gestão e do desempenho da equipe de trabalho faz-se necessários verificar e valorizar os "múltiplos olhares", já que:

Para identificar o valor percebido por um consumidor, é preciso investir em conhecimento, o que significa levantar informações que assegurem melhor tomada de decisão. Ou seja, por meio de pesquisas é possível determinar o que o cliente quer e $o$ que ele espera de um serviço, como ele percebe o serviço. Uma vez mensurado o valor percebido pelo cliente, é possível estabelecer uma estratégia sobre o que realmente tem significado e importância para esse cliente.

Mensurado o valor percebido pelo cliente por meio de investigação é preciso comunicar na propaganda os pontos de valor que realmente os clientes daquele serviço buscam (DIAS, 2010, p. 504).

\section{PROCEDIMENTOS METODOLÓGICOS}

A seguir serão explanados os procedimentos metodológicos, que compreendem: a caracterização do ambiente da pesquisa; as técnicas de pesquisa empregadas; a caracterização da população-alvo e amostragem; e as estratégias de coleta de dados empregadas na efetivação desse trabalho. 
Revista ACB: Biblioteconomia em Santa Catarina, Florianópolis, v. 22, n. 2, ESPECIAL, p. 192-207, abr./ jul., 2017.

Anais do $35^{\circ}$ Painel Biblioteconomia Santa Catarina.

Chapecó

\subsection{Caracterização do ambiente de pesquisa}

O estudo foi realizado na Biblioteca Setorial do Centro de Educação (CE) da Universidade Federal do Espírito Santo (Ufes). A Biblioteca $\mathrm{CE}^{6}$ tem como objetivo principal dar suporte às atividades de ensino, pesquisa e extensão. Dentre as metas para o futuro está o aumento do acervo, bem como a manutenção de sua atualidade. Essa biblioteca oferece os seguintes serviços: empréstimo de livros e multimeios, empréstimo entre bibliotecas, renovação e reserva de livros e multimeios, acesso a periódicos, acesso ao portal de periódicos da CAPES.

Em 2009, por solicitação da Direção do CE a Biblioteca passou a integrar o SIB/Ufes ${ }^{7}$, que é constituído por oito bibliotecas sendo que a Biblioteca Central (BC) - enquanto órgão coordenador do Sistema Integrado de Bibliotecas da Ufes (SIB/Ufes) usuárias da Rede Compartilhada do Sistema Pergamum (um sistema gerenciador de dados, direcionado aos diversos tipos de Centros de Informação, tendo sede na Pontifícia Universidade Católica do Paraná, cidade de Curitiba).

Atualmente o setor conta com um acervo de aproximadamente 4.100 títulos e 8.060 exemplares, 52 títulos de periódicos. O horário de funcionamento é de segunda a sexta-feira das 07:00 às 21:00 horas e faz, em média, 920 atendimentos mensais.

\subsection{Técnicas de pesquisa}

Para a realização do levantamento escolhemos como técnica de coleta de dados o questionário, semiestruturado, com alternativas de resposta dispostas em escala Likert $^{8}$ de 5 pontos. Não existe um número obrigatório de atributos, embora o mais comum seja usar os 22 sugeridos em Parasuraman, Zeithaml e Berry (1985). A operacionalização desse método se dá pelo cálculo da diferença entre as percepções de desempenho e as expectativas de serviço. Todavia, a literatura recomenda a adaptação à situação estudada, mantendo o cuidado para que a extensão do questionário não prejudique as respostas.

\footnotetext{
6 É importante notar que a Biblioteca CE/Ufes foi criada em 1994 e, atualmente, encontra-se no andar térreo do Edifício Maria de Jesus de Oliveira Borgo (IC-IV), mais conhecido como prédio novo da Pedagogia,no Campus Universitário de Goiabeiras.

7 Sistema Integrado de Bibliotecas (SIB) da Universidade Federal do Espírito Santo (Ufes) conta com oito unidades: Biblioteca Central (BC) Fernando de Castro Moraes [responsável por coordenar todo o Sistema], Biblioteca Setorial Tecnológica, Biblioteca Setorial Ciências da Saúde, Biblioteca Setorial do Centro Universitário Norte do Espírito Santo (Ceunes), Biblioteca Setorial de Ciências Agrárias, Biblioteca Setorial de Artes, Biblioteca setorial do Centro de Educação (CE) e Biblioteca Setorial do Núcleo de Estudos e de Difusão de Tecnologia em Floresta, Recursos Hídricos e Agricultura Sustentável (Nedtec).

8 A Escala Likert é uma escala psicométrica das mais conhecidas e utilizadas em pesquisas quantitativas, usada para avaliar o nível de concordância ou discordância com à mesma. Usualmente são usados cinco níveis de respostas, os clientes deveriam assinalar uma opção entre 1 e 5 da escala Likert (sendo que na escala $1=$ menos pertinente e $5=$ muito pertinente) para as 22 pares de questões (importância x satisfação). A escala tipo Likert exige resposta graduada para cada afirmação e, geralmente servem para mostra os extremos, sendo que o ponto intermediário (grau 3) representaria o indeciso ou apático.
} 
Revista ACB: Biblioteconomia em Santa Catarina, Florianópolis, v. 22, n. 2, ESPECIAL, p. 192-207, abr./ jul., 2017. Anais do $35^{\circ}$ Painel Biblioteconomia Santa Catarina.

Chapecó

Em convergência com Crossno et al. (2001), preferimos utilizar o termo "importância" ao invés de expectativas, proposto pelo método Servqual, porque essa abordagem teórico-metodológica permite ajustes e, também concordamos com a utilização realizada por Brito e Vergueiro (2011) os quais admitem que essa estrutura gera simplificação e facilitação, sendo assim, é mais fácil para o participante entender: "o quanto atendimento é importante para você" do que "qual a sua expectativa em relação ao atendimento". Pela mesma razão, percepção foi substituída por satisfação na esquematização das questões.

\subsection{Caracterização da população-alvo e amostra}

A população-alvo foi constituída pelo conjunto de usuários (230 atendidos semanalmente) que utiliza os serviços da Biblioteca (discentes de graduação e pós-graduação, técnicos e docentes do CE). A amostra (representativa) selecionada é não probabilística acidental (por conveniência), e reuniu 145 $(18,13 \%)$ usuários aos quais foram aplicados o questionário adaptado da abordagem teórico-metodológica Servqual.

\subsection{Estratégias de coleta de dados}

Cabe observar que as sentenças adotadas no presente estudo podem não ter representado a totalidade de atributos relevantes ao julgamento da qualidade do serviço estudado. No entanto, como já tinha havido validação prévia nos estudos citados (NITECKI; HERNON, 2000; BRITO; VERGUEIRO, 2011; MIGUEL; FREIRE, 2016), admitiu-se que sua replicação conferiria certa segurança e praticidade na aplicação da pesquisa.

Como sempre ocorre a situação de coleta, apesar de cercada de cuidados para promover uma atmosfera adequada ao preenchimento do instrumento de pesquisa, não estava livre de interferências por isso disponibilizamos o questionário na internet para que os usuários pudessem acessá-lo a partir qualquer ambiente, objetivando facilitar o preenchimento. O questionário online ${ }^{9}$ ficou disponível no período de 1 a 30 de novembro de 2016 (30 dias do período letivo) e os usuários foram convidados a participar da pesquisa (não havendo a obrigatoriedade de adesão à atividade).

O procedimento de coleta de $\operatorname{dados}^{10}$ se deu de forma aleatória conforme abordagem e disponibilidade da comunidade usuária dessa biblioteca. Utilizou-se o programa Excel, da Microsoft, suas

\footnotetext{
${ }^{9}$ Construído mediante a utilização da ferramenta Google Forms - do Google Docs. O Formulário Google Drive pode ser conectado a planilhas e essas vinculadas a um formulário captam automaticamente numa planilha.

10 Os dados coletados foram inseridos e tabulados no software Excel (programa de planilha eletrônica) da Microsoft e utilizamos fórmulas estatísticas para calcular as médias, proporções, frequências relativas para produzir as tabelas e gráficos,
} 
Revista ACB: Biblioteconomia em Santa Catarina, Florianópolis, v. 22, n. 2, ESPECIAL, p. 192-207, abr./ jul., 2017. Anais do $35^{\circ}$ Painel Biblioteconomia Santa Catarina.

Chapecó

fórmulas e funções estatísticas para calcular as médias, proporções, frequências relativas visando produzir as tabelas e gráficos para apresentar nas seções a seguir.

\section{APRESENTAÇÃO E ANÁLISE DE DADOS}

Essa seção apresenta os resultados provenientes da pesquisa quantitativa, os dados foram divididos, sintetizados e apresentados em três blocos de análise, a saber: primeiramente, serão apresentados as características gerais e, na sequência, dois blocos abordaram a abordagem teórico-metodológica Servqual. Cabe lembrar,que a última seção apresenta Análise de Gaps e a Matriz de Importância x Desempenho definindo possibilidades e estratégias a serem utilizadas para melhorar a gestão e o processo de desenvolvimentos de serviços da unidade de informação.

\subsection{Características gerais}

Do total de 145 respondentes, quanto ao gênero, 95 (65,52\%) feminino e 50 (34,48\%) masculino. Em termos de faixa etária, $69(47,56 \%)$ dos sujeitos tinham entre 18 e 29 anos. Destaca-se também a representatividade da faixa etária compreendida entre 30 e 45 anos (42,07\%).

Em relação ao tipo de usuário da biblioteca, constatou-se que 107 (73,79\%) eram alunos da graduação sendo: $85(79,44 \%)$ alunos do Curso de Pedagogia localizado no CE e os outros $22(38,60 \%)$ alunos estão matriculados nos cursos de administração, arquivologia, biblioteconomia, ciências sociais, comunicação social, filosofia, geografia, história, letras, oceanografia e química. Destaca-se ainda a participação dos mestrandos $16(11,03 \%)$ e de 11 (7,59\%) doutorandos do PPGE e, de 11 (7,59\%) alunos de cursos de especialização ofertados pelo CE.

Quanto à frequência à Biblioteca 57 (39,31\%) dos participantes comparecem à biblioteca ao menos uma vez por semana, 39 (26,90\%) participantes a frequentam ao menos uma vez por quinzena e outros 30 (20,69\%) participantes a frequentam ao menos mensalmente, frequência essa que pode ser considerada alta a julgar pelos prazos de devolução dos empréstimos da biblioteca, em geral, de quatorze dias podendo ser renovado pelo usuário desde que não esteja em atraso e que não haja solicitação de reserva.

visando facilitar a descrição dos dados recolhidos. Cabe lembrar, que existe no mercado vários programas como características similares e que podem ser utilizados nesse mesmo intuito, como exemplo: o LibreOffice Calc, Zoho Sheet, Polaris Office, Apache OpenOffice Calc, Google Sheets, BrOffice.org Calc, Google Drive e outros. 
Revista ACB: Biblioteconomia em Santa Catarina, Florianópolis, v. 22, n. 2, ESPECIAL, p. 192-207, abr./ jul., 2017.

Anais do $35^{\circ}$ Painel Biblioteconomia Santa Catarina.

Chapecó

\subsection{Importância e satisfação por dimensão conforme o método servqual}

Para fins de estruturação do texto, os dados são apresentados tomando-se como eixos as dimensões (empatia, garantia, receptividade, confiabilidade, tangibilidade) da qualidade que caracterizam o Método Servqual, as quais foram utilizadas também para a elaboração do instrumento de coleta de informações.

Tabela 1 - Importância e Satisfação por Dimensão

\begin{tabular}{ccc}
\hline & Importância & Satisfação \\
\hline Empatia & 4,54 & 3,54 \\
Garantia & 4,64 & 3,97 \\
Receptividade & 4,71 & 3,90 \\
Confiabilidade & 4,78 & 4,06 \\
Tangibilidade & 4,27 & 3,40 \\
\hline
\end{tabular}

Fonte: Dados da pesquisa, 2016.

Pode-se observar os graus de importância atribuídos pelos respondentes considerando as dimensões da qualidade, a saber: Confiabilidade (4,78), seguida de Receptividade (4,71), Garantia (4,64) e Empatia $(4,54)$, sendo a menos valorizada foi a Tangibilidade $(4,27)$. No que se refere à satisfação, observa-se que a dimensão mais valorizada foi a Confiabilidade (4,06), seguida de Garantia $(3,97)$, Receptividade $(3,90)$, e Empatia (3,54). A dimensão da com maior insatisfação é a Tangibilidade $(3,40)$ conforme a tabela 1.

\subsection{Análise de gaps e quadrantes}

Conforme Brito e Vergueiro (2011) há uma segunda maneira para apresentar os resultados de pesquisas que usam o método Servqual. Análise de Gaps compreende o diagnóstico das lacunas apuradas nas questões das dimensões da qualidade. Para o cálculo dos Gaps, utiliza-se a seguinte fórmula: Gap = Satisfação - Importância

Para calcular as médias, as pontuações (de 1 a 5) de cada questão foram somadas e depois divididas pelo número total de respondentes (145) tanto para a satisfação quanto para a importância. A seguir foi calculada a diferença entre as duas, obtendo-se assim o Gap por questão. Também é possível verificar que o grau de exigência do público pesquisado é alto. A média das importâncias dadas pelos pesquisados às dimensões de qualidade variara entre 4,27 e 4,78.

Assim sendo, estudos de Nitecki e Hernon (2000) indicam que as pontuações de Gaps entre 0 e -1 não superam as expectativas, porém podem atender ao que os usuários realmente esperam de um serviço de qualidade, pode-se dizer que a comunidade acadêmica do CE percebe positivamente a qualidade dos serviços prestados pelo SR. 
Revista ACB: Biblioteconomia em Santa Catarina, Florianópolis, v. 22, n. 2, ESPECIAL, p. 192-207, abr./ jul., 2017.

Anais do $35^{\circ}$ Painel Biblioteconomia Santa Catarina.

Chapecó

O maior Gap foi identificado na dimensão Empatia $(0,99)$ e o menor é Garantia $(0,67)$. Entre os critérios que compõem as cinco dimensões, vimos que Confiabilidade apresenta maior importância $(4,78)$ e melhor satisfação $(4,06)$.

Para o cálculo dos Gaps por dimensão foram somadas as médias das questões de cada dimensão e divididas pelo total de questões de cada dimensão da qualidade do questionário da pesquisa. Por exemplo, para o cálculo dos Gaps da dimensão "Receptividade" foram somadas as médias das pontuações das questões relativas a esta dimensão e depois divididas por três, número das questões relacionadas a esta dimensão. O Gráfico 1 apresenta os Gaps por dimensão:

Gráfico 1 - Gaps por dimensões

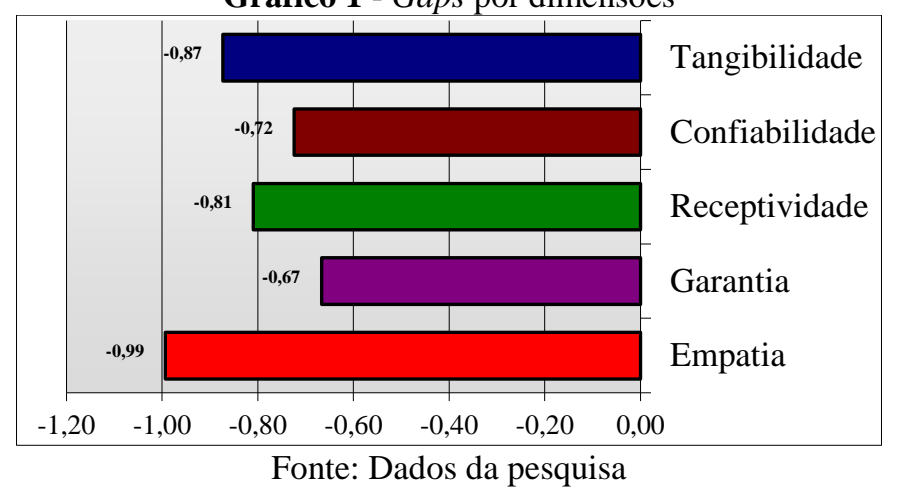

A partir do Gráfico 1 pode-se deduzir que o item com o maior Gap na opinião dos participantes foi Empatia, que de acordo com o método Servqual, refere-se ao cuidado em oferecer atenção individualizada aos usuários.

Já a Matriz de Análise de Importância e Desempenho ${ }^{11}$ (Matriz Análise de Quadrantes) constitui-se uma ferramenta teórico-metodológica para que a instituição tenha uma visão estratégica sobre quais os atributos deveria melhorar, para tornar-se mais competitiva no mercado, sendo assim, podemos dizer que a análise de quadrantes é uma boa forma de se apresentar os resultados do método Servqual. Nitecki e Hernon (2000) recomendam-na devido a correlação gráfica que facilita a visualização dos dados.

Ao aplicar a análise de quadrante verificam-se informações bastante interessantes sobre o SR da Biblioteca/CE e, nesta pesquisa ocorreu uma concentração no quadrante 1 (manter) de todos os vinte e dois atributos da qualidade. Isso sugere que os clientes veem todos os atributos da pesquisa como importantes e bem desempenhados pela biblioteca, como pode ser vislumbrado na Figura 1.

\footnotetext{
${ }^{11}$ Matriz bidimensional, é dividida em quatro quadrantes: no Quadrante I os atributos situados tem alta importância com alto desempenho, representando uma possível vantagem competitiva. Um atributo que tiver alta importância, mas baixo desempenho, deverá receber atenção imediata, constando no Quadrante II. O Quadrante III concentra os atributos com alto desempenho, porém com baixa importância. O Quadrante IV contém os atributos com baixa importância e baixo desempenho, não sendo necessário concentrar esforço adicional.
} 
Figura 1 - Análise de Quadrantes

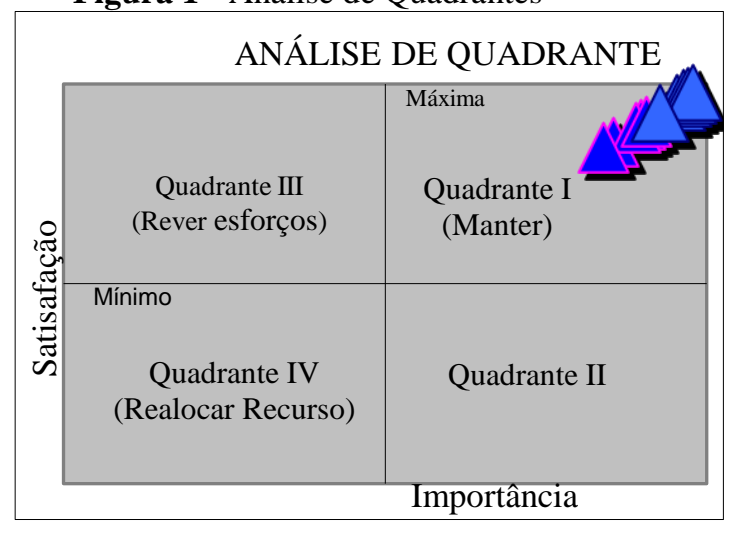

Fonte: Dados da pesquisa, 2016

\section{CONSIDERAÇÕES E RECOMENDAÇÕES}

Retomamos que objetivo principal dessa pesquisa foi avaliar a qualidade dos serviços prestados no que tange a expectativa e a percepção dos usuários em relação ao SR da Biblioteca do CE/Ufes. Reiteramos que alguns resultados levam a inferir que algumas ações devem ser definidas pela Biblioteca visando a melhorar a satisfação de seus usuários. Verificamos que se, de um lado, temos bons resultados no que concerne ao grau de confiabilidade por parte dos respondentes, do outro; faz-se necessário incrementar a dimensão "empatia", pois a primazia do serviço deve estar pautada na boa capacidade de negociação, na liderança situacional e na habilidade de comunicação. Consideramos que a dimensão Empatia está diretamente relacionada à dimensão Confiabilidade, pois em se tratando de um SR, o conhecimento tácito do bibliotecário (know-how), na opinião dos usuários o mesmo agrega valor ao atendimento prestado.

Um dos pontos fracos refere-se a tangibilidade, demonstrando se que há necessidade de investir na melhoria da infraestrutura física e tecnológica, bem como no processo de humanização do acolhimento aos usuários por parte dos técnicos da Ufes. Esses resultados permitem sugerir que algumas ações específicas sejam consideradas, tais como: 1 - implementar rede local sem fio, wi-fi. 2 - investir na melhoria da ambientação física, especialmente na climatização e ampliação do espaço físico; 3 - definir uma política de desenvolvimento de competências em informação, pois nem todos os usuários são autônomos na busca e recuperação da informação utilizando os sistemas informatizados ou serviços disponibilizados via web.

Esta pesquisa realizada para avaliar a qualidade do SR da CE/Ufes, a exemplo de outros realizados em bibliotecas acadêmicas, comprovou que realmente o método Servqual é apropriado para avaliar a qualidade a partir das percepções e expectativas dos usuários. Portanto, o método pode ser considerado 
Revista ACB: Biblioteconomia em Santa Catarina, Florianópolis, v. 22, n. 2, ESPECIAL, p. 192-207, abr./ jul., 2017.

Anais do $35^{\circ}$ Painel Biblioteconomia Santa Catarina.

Chapecó

ferramenta útil para a gestão e a tomada de decisões, pois permite evidenciar os pontos fracos e fortes das organizações sob a ótica da clientela.

Em meio às vantagens do método em questão há uma desvantagem, qual seja: o questionário padrão do Servqual é constituído apenas por questões fechadas o que o caracteriza como um método quantitativo. Porém, nesta pesquisa, buscamos suprir essa lacuna inserindo questões abertas. Nessa direção, ao dar voz aos usuários também por essa via, além de agregarmos valor qualitativo ao estudo de usuários, reunimos informações explícitas que propiciam o monitoramento organizacional, hoje, tão significativo para o desenvolvimento das organizações.

O tema não foi esgotado, e outras reflexões podem ser propostas, bem como sugerimos explorar mais a parte qualitativa da abordagem teórico-metodológica Servqual promovendo um diagnóstico minucioso da ambiência dessa instituição acadêmica, e outras escalas podem ser utilizadas, tal como: o LibQUAL+ e o SERVPERF. Portanto, possíveis desdobramentos podem fundamentar uma continuidade nessa linha de pesquisa visando atender aos múltiplos olhares (dos usuários) sobre o processo de desenvolvimento de serviços.

Considera-se ainda que, para uma difusão ampliada de estudo realiza em pró da qualidade de serviços biblioteconômicos, é preciso, mais que tudo, compartilhar e fomentar como os pares profissionais da informação - as abordagens teóricas e metodológicas da Gestão da Qualidade que forem eficientes, ou não, considerando seu contexto. Lembrando ainda que existem muitos diagnósticos e práticas sobre a qualidade e o desenvolvimento de serviços feitos, mas que não são compartilhados.

Finalmente, cabe ressaltar que todo esse elenco de preocupações deve ser levado em consideração sem se perder de vista que a os modelos de avaliação da qualidade dos serviços nas bibliotecas universitárias são instrumentos essenciais de aferição de diagnósticos dos pontos fortes, fracos que se podem exprimir em oportunidades de aplicabilidade de Boas Práticas (best practices) e inovação, quando corretamente implementados e empregados, identificando causas e encontrando soluções criativas nas tomadas de decisão com vista a melhorar o desempenho na prestação de serviços biblioteconômicos.

\section{REFERÊNCIAS}

ACCART, Jean-Philippe. Serviço de referência: do presencial ao virtual. Brasília, DF: Briquet de Lemos/Livros, 2012. 312 p.

ALMEIDA JÚNIOR, Oswaldo Francisco de. Biblioteca pública: avaliação de serviços. Londrina: EDUEL, 2003. 288 p.

ARAÚJO, Carlos Alberto Ávila. Estudos de usuários conforme o paradigma social da ciência da informação: desafios teóricos e práticos de pesquisa.Informação \& Informação, Londrina, v. 15, n. 2, p. 23 - 39, jul./dez. 2010 
Revista ACB: Biblioteconomia em Santa Catarina, Florianópolis, v. 22, n. 2, ESPECIAL, p. 192-207, abr./ jul., 2017. Anais do $35^{\circ}$ Painel Biblioteconomia Santa Catarina.

Chapecó

ASSIS, Renato Viola de. Dinâmica organizacional da empresa moderna: as relações de trabalho frente às transformações político-econômicas do século XXI. 2008. [97], 158 f. Dissertação (Mestrado Em Direito) - Universidade Metodista de Piracicaba. Disponível em:

<www.unimep.br/phpg/bibdig/pdfs/2006/RGCNTLPJMVJB.pdf >. Acesso em: 19 dez. 2016.

BERRY, Leonard L.; PARASURAMAN, A. Serviços de marketing: competindo através da qualidade. São Paulo: Maltese: Norma, c1992. 238 p.

BRITO, Gisele Ferreira de; VERGUEIRO, W. C. S. Avaliação da qualidade orientada ao usuário: estudo de caso em biblioteca acadêmica utilizando o método servqual. In: CONGRESSO BRASILEIRO DE BIBLIOTECONOMIA E DOCUMENTAÇÃO, 2011, Maceió. Disponível em:

<www.redalyc.org/articulo.oa?id=181422294009>. Acesso em: 08 mar. 2013.

CROSSNO, J. E. et al. Assessment of customer service in Academic Health Care Libraries (ACSAHL): an instrument for measuring customer service. Bulletin of the Medical Library Association v. 89, n. 2, pp. 170-176, Abr. 2001. Disponível em: <http://www.ncbi.nlm.nih.gov/ pmc/articles/PMC31724/> .

Acesso em: 17 mar. 2013

DIAS, Sérgio Roberto (Coord.). Gestão de marketing. 2. ed. São Paulo: Saraiva, 2010. xviii, 539 p.

FERREIRA, S. M. S. P. Novos paradigmas e novos usuários de informação. Ciência da Informação, Brasília, v. 25, n. 2. 1995. Disponível em:

<http://revista.ibict.br/ciinf/index.php/ciinf/article/download/440/398>. Acesso em: 02 fev. 2013

FIGUEIREDO, Nice Menezes de. Paradigmas modernos da ciência da informação. São Paulo: Polis, 1999. $167 \mathrm{p}$.

FONSECA, Edson Nery da. Introdução á biblioteconomia. 2. ed. São Paulo: Briquet de Lemos, 2007, $152 \mathrm{p}$.

GONÇALVES, Ana Lúcia Ferreira. Gestão da informação na perspectiva do usuário: subsídios para uma política em bibliotecas universitárias. Niterói: Intertexto, 2013.

GROGAN, Denis Joseph. A prática do serviço de referência. Brasília, DF: Briquet de Lemos/Livros, 1995. 196p.

LANCASTER, F. Wilfrid. Avaliação de serviços de bibliotecas. Tradução de Antonio Agenor. Brasília, DF: Briquet de Lemos, 1996. 356 p.

META DA UFES É AMPLIAR A QUALIDADE. UNIVERSIDADE: revista da Universidade Federal do Espírito Santo - UFES. Vitória (ES): UFES, n.1, p. 56-57, Jan/Abr, 2013-. Quadrimestral.

MIGUEL, M. C; FREIRE, V. F. Avaliação da Qualidade Orientada ao Usuário do Museu Capixaba do Negro: Aplicação da Abordagem Teórico-Metodológica Servqual em um Espaço Museológico de VitóriaES. Revista Guará, Vitória, n. 05, p. 103-116, Jul, 2016. Disponível em: <http://periodicos.ufes.br/guara/article/view/14350/10092>. Acesso em: 19 jul. 2016.

NITECKI, D. A.; HERNON, P. Measuring service quality at Yale's University's libraries. The Journal of Academic Librarianship, Ann Arbor, v. 26, n. 4, p. 259-273, Jul. 2000.

PARASURAMAN, A; ZEITHAML, V. A; BERRY, L. L. A conceptual model of service quality and its implications for future research. Journal of Marketing, Chicago, v. 49, n. 4, p. 41-50, Fall 1985. 
Revista ACB: Biblioteconomia em Santa Catarina, Florianópolis, v. 22, n. 2, ESPECIAL, p. 192-207, abr./ jul., 2017. Anais do $35^{\circ}$ Painel Biblioteconomia Santa Catarina.

Chapecó

MULTIPLE LOOKS IN BEHALF OF THE QUALITY OF LIBRARY SERVICES: Servqual and the process of developing services in an academic library in the $21^{\text {st }}$ century

\begin{abstract}
Evaluates the quality of services provided in the Reference Service of the Sectoral Library of the Education Center of the Federal University of Espirito Santo (UFES) usingthe Servqual method. It examines the importance and satisfaction matrix as a tool for analyzing the data in relation to the five dimensions of quality: Reliability, Empathy, Assurance, responsiveness and tangibility. The methodology of this study has a descriptive character of quantitative nature. Its design is of the survey type with the use of semi-structured online questionnaire. The results obtained in this research evidence that customers consider the Tangibility dimension important, however, there is dissatisfaction. Recommends the Servqual method for assessing the quality of an academic library.
\end{abstract}

Keywords: Servqual. Reference Services. Quality. Academic Library.

\title{
MARCELO CALDERARI MIGUEL
}

Possui graduação em Biblioteconomia pela Universidade Federal do Espírito Santo (Ufes), Bacharelado em Ciência Contábeis pela Faculdade de Estudos Administrativos de Minas Gerais (FEAD) e Aperfeiçoamento em Educação Científica: Educação não formal em Ciência e Tecnologia pela Universidade Federal de Minas Gerais (UFMG). Atualmente, é discente do Curso de Administração (Ufes) e da pós-graduando em Matemática Financeira e Estatística; atua no ramo da Consultoria Informacional, com foco em normalização, estruturação e revisão de projetos e pesquisas acadêmicocientíficas; ministra aulas sobre metodologia científica; e é pesquisador atuante no ramo da Educação a distância, Educação não formal em Ciência e Tecnologia, Normalização de Trabalhos Científicos e na Produção \& Avaliação de Materiais didático-pedagógicos. 